\title{
An Assessment of the 2009 Zimbabwe Government's Decision to Enrol Pupils into Form One Using School-Based Assessment as an Alternative to Public Examinations
}

\author{
Misheck Mhishi $^{1}$, Edward Mandoga ${ }^{1}$, Nyarai Tunjera ${ }^{1}$ \& Crispen Erinos Bhukuvhani ${ }^{1}$ \\ ${ }^{1}$ Department of Science Education, Bindura University of Science Education, Zimbabwe \\ Correspondence: Misheck Mhishi, Department of Science Education, Bindura University of Science Education, \\ Zimbabwe. E-mail: mhishimisheck@yahoo.com
}

Received: April 9, 2012 Accepted: April 11, 2012 Online Published: June 15, 2012

doi:10.5539/ies.v5n4p31 URL: http://dx.doi.org/10.5539/ies.v5n4p31

\begin{abstract}
School-Based Assessment (SBA) can help achieve a holistic, child-centred and qualitative account of a pupil's performance. The same method has been criticised for being subjective, informal and open to teacher bias hence the reluctance by the Zimbabwe Schools Examination Council (ZIMSEC) to embrace it for certification and selection into further education or vocational careers. In 2009, the prohibitive cost of administering national examinations due to economic problems faced by the country and the subsequent delays in releasing the results forced The Ministry of Education, Sport, Arts and Culture to enrol pupils from primary into secondary schools using SBA results. This survey, conducted using both qualitative and quantitative methods, was carried out at three purposively sampled secondary schools (162 pupils) and looked at whether there was consistency between the national examinations and the SBA results used to enrol pupils. A questionnaire with both open-ended and closed questions was used to collect data. Seven primary school trained teachers were interviewed to ascertain their knowledge on SBA and all of them had not received any formal training on SBA. Results obtained reveal that SBA can be a trusted benchmark for promotion of pupils from primary into secondary school as those pupils who passed teacher tests at Grade Seven also passed the ZIMSEC national examinations. In order to achieve efficient use of limited financial resources, the study recommends that the promotion of pupils into Form One be done using SBA results and that pre-service and in-service training of teachers on SBA be made a priority.
\end{abstract}

Keywords: school-based assessment, national examination, primary school, secondary school

\section{Introduction and Background to the Study}

All over the world, a number of countries are reforming their educational systems from being teacher dominated to become child-centred. School-Based Assessment (SBA) which is done at school level attempts to empower the learner and if correctly implemented and incorporated into summative assessments, a more comprehensive and cumulative judgement about the pupils is achieved (Masole, 2004). In Zimbabwe, School-Based Assessment is not a common feature in the examination system as only practical subjects make use of it. In these subjects, school-based assessment may be in the form of a project, a portfolio, or a practical test. The marks from these tasks are validated by moderators sent by the examination board to verify the marks. In the other subjects that make up the school curriculum, the issues of validity and reliability may have delayed the inclusion of school-based assessment in the summative assessments. Masole, (2005) notes that validity and reliability are a result of factors which include those that are found within the school set up and control, such as pedagogical techniques, strategies of assessment, remedial teaching, teachers' cooperation and supervision and those that are out of the school's control like the provision of resources, teacher competence, teaching loads and moderation.

The government of Zimbabwe has always taken the education of its citizens seriously throughout the years. This is evidenced by the huge investments and efforts it has made to increase participation through the policy of Education for All (Shizha \& Kariwo, 2011). A lot of resources have been channeled into infrastructure development, education research and teacher training courses, books and stationery, payment of tuition and examination fees for the disadvantaged pupils, supplementary feeding and many other initiatives (Chung,2009;CSO and UNICEF,2009). The Zimbabwe Schools Examinations Council (ZIMSEC), a parastatal body whose mandate was to oversee the research, testing and the impartial measurement of performance of four 
major summative examinations in the country was also founded. The first examination under ZIMSEC is at the end of seven years in primary school. Results from this examination are used by secondary schools for enrollment into Form One. At the end of two years in secondary school, students used to sit for the second examination, the Zimbabwe Junior Certificate in Education examination which has been shelved. At the end of secondary school, Ordinary Level examinations are administered, the results of which determine who moves into Form Five, tertiary education or the vocational/occupational field. After two years in high school, Advanced Level examinations are held and these affect the students' entry into University or the job market (Zvobgo, 1997). These examinations are set at National level and written at a particular time and date all over the country. Rubadiri (2005) and Sommerset (1987) call such examinations high stakes because the results from these examinations are used for serious categorization of pupils that is for certification and selection into further education or vocational careers. This places enormous pressure on the students, parents, teachers and the society at large. Cases of cheating during examinations and suicide by those who would have failed these examinations have been reported in Zimbabwe, Malawi, Mozambique and other countries (Rubadiri, 2005; De Assis, 2005). As a result, calls have been made to consider using School-Based Assessment results as part of the summative tests.

In 2008 Zimbabwe experienced serious problems of hyper-inflation resulting from political and economic crises. These problems resulted in the death and a decline in the education standards, amongst other sectors (Shizha \& Kariwo, 2011). Many teachers left the country (Chetsanga, 2000) and those that remained went on protracted industrial action for most of the year. It was therefore, generally assumed that no proper teaching and learning took place in the year 2008. Against this background, Grade Seven pupils went on to sit for their end of course examinations.

The harsh economic conditions adversely affected the running of all national examinations. ZIMSEC found the cost of administering these examinations too high and had to be bailed out by the Reserve Bank of Zimbabwe. The Reserve Bank provided transport to ferry the examination materials across the country and proceeded to pay the invigilators. Even then, the Examinations Board failed to recruit and pay examiners on time which subsequently delayed the release of results. This sad state of affairs forced the Ministry of Education, Sport, Arts and Culture to direct all schools to enroll pupils into Form One and Five using SBA results (Chirume, Dirwai \& Masiri, 2009). This decision was met with mixed reactions from education stakeholders some of whom viewed teachers' assessment results as an unsuitable replacement for public examinations. This was despite the fact that the same method was used for practical subjects at O' and A' levels as well as at tertiary institutions with very few objections being raised.

The prevailing situation in Zimbabwe then, presented the country with an opportunity to 'test-drive' SBA as a method of promoting pupils into Form One and Five. In such a scenario, this research will, therefore, seek answers to the following research questions:

i. Can School-Based Assessment (SBA) be used as a valid instrument of enrolment of students into Form One?

ii. How do the students view the use of School-Based Assessment (SBA) results for enrolment into Form One as opposed to the ZIMSEC examination results?

iii. Do the teachers have any formal training in administering SBA?

\section{Statement of Hypotheses}

The Hypotheses which were tested were:

a) The Null Hypothesis (H0) which states that there is no relationship between pupils' performance at School Based Tests (SBA) and their performance at ZIMSEC Grade 7.

b) The Alternative Hypothesis (H1) stating that there is a relationship between pupils' performance at School Based Tests (SBA) and their performance at ZIMSEC Grade 7.

\section{Literature Review}

In some African countries, the use of School-Based Assessment results in summative examinations has been implemented, though with varying degrees of success. Examples include Kenya, Lesotho, Namibia, Nigeria, Swaziland, Tanzania, Uganda, Bangladesh and Guinea (Nitko, 2004; Chisholm, 2004; Kellaghan \& Greaney, 2004, Dirwai, 2004, Ndabi, 2004; Begum, 2008). In South Africa, up to Grade Nine, School-Based Assessment results constitute $75 \%$ of the final assessment (Monageng \& Pillay, 2005) and in Bangladesh, promotion to the 
next junior secondary level of general education takes into account not only the examination results, but also on the student's performance in the year as well as their personal development (Begum, 2008).

The successful implementation of continuous assessment hinges upon the quality of the teacher (Ogunniyi, 1991 and Plake \& Impara, 1997). They point out that teachers need adequate knowledge on developing valid and reliable testing instruments, know how to assess non-cognitive aspects of the learning process, how to interpret assessment results as well as the keeping of accurate records. Researches undertaken in many African countries revealed that low teacher competence levels may affect assessment results. In some instances, it was found out that few pupils' work contained teachers' comments either to commend good work or to identify problems. Little homework was given, marking was rarely done and the teaching-learning process was teacher centred. In some cases no questions were asked at all and when asked, these were closed, rhetoric and appealed to the low order cognitive skills and pupils answered in chorus. This was especially true for Tanzania, Swaziland and Kenya (Kellaghan and Greaney, 2004; Kaira, 2005 and Ogunniyi, 1991).

In order to enhance the quality of teacher competence in school-based assessments, there's need to provide continuing professional development to the teachers through pre-service and in-service programmes (Craig and Perraton, 2003). Education experts warn that if teachers are not well-equipped and confident in their work, they may succumb to pressure and corruption from some parents who want good grades for their children or they may not want to be blamed for the pupils' failure hence they end up inflating scores. Kaira, (2005) points out that continuous assessment results in Tanzania were consistently higher than those from public examinations and this was attributed to favouritism and teacher biases on gender, socio-economic background or personality.

The Zimbabwe education system has had in place some programmes of continuing professional development. These have included the Better Schools Programme Zimbabwe (BSPZ) and the Science Education In-Service Teacher Training (SEITT) which are run in conjunction with The Ministry of Education, Sport, Arts and Culture (Mtetwa, Makamure, Kwari and Chipangura, 2003). Dirwai (2004) suggests that teachers could be trained in school-based assessment through such institutions.

\section{Justification of the Study}

School-Based Assessment has been used in Zimbabwe's practical subjects and when internally assessing pupils. It has also been useful when enrolling pupils to the next grade within the same level of education and when acquiring a place after a transfer from one school to another. As a policy in Zimbabwe, school leavers are still judged on a single examination which determines whether they pass or fail. However, in 2009, the failure by ZIMSEC to release Grade Seven, Ordinary and Advanced Level results on time forced schools to resort to the use of School-Based (mid-year results) for the enrollment of pupils into Forms One and Five.

Mortimore and Mortimore (1984), and Mathews (1985) pointed out that National Assessment Systems are expensive and time consuming especially for the developing countries who have limited human and financial resources. They encouraged that measures be put in place to ensure that assessments were carried out by methods that were fair, economic and relevant to these countries. If properly implemented, School-Based Assessment and Ethno-Based teaching and learning could bring about equity and fairness in the country's education system (Tirivarombo, 2004; Maravanyika, 2004; http:curriculum.w.cape.school.za/resourcefiles).

Some African countries like Malawi saw improved pass rates in basic literacy and numeracy skills after the implementation of SBA; Namibia successfully integrated SBA with the summative assessments and in Tanzania $50 \%$ of Ordinary and Advanced level examination results is obtained from School-Based Assessments (Kaira, 2005). In Zimbabwe, the use of School-Based Assessment results in the recruitment of Forms One and Five came at an opportune time when Zimbabwe needed to think critically about the advantages of using School-Based Assessment in summative tests.

The impromptu decision to use continuous assessment results as entry requirements into Form One gave this study an opportunity to come up with fairly objective SBA results as teachers compiled the results without prior knowledge that they would influence policy makers to promote pupils into Form One. Results were therefore gathered from a 'natural' set up hence were likely to be less affected by teacher biases.

This research was envisaged to benefit the policy makers on the use of SBA. It also has some implications on ZIMSEC as an examination body as it might consider incorporating an SBA component in its summative assessment of pupils in Zimbabwe. The study might also benefit the academic world as it might boost confidence in the use of SBA. The region might also benefit as Zimbabwe would have offered a case study on how SBA was successfully used to recruit pupils to the next grade and level. 


\section{Limitations of the Study}

The present study sought to find out how authentic the School-Based Assessment results used at Form One recruitment were as compared to the ZIMSEC results. It has to be noted that in setting mid-year examinations in the schools, many teachers use items from the ZIMSEC examinations (Dirwai, 2004). These tests focus only on the cognitive domain and ignore some essential qualities such as oral presentation skills, co-curricular activities and other social values which advocates for SBA feel should be examined (Begum, 2008). By focusing on the pupils' mid-year results which did not include results from portfolios, projects and homework, the study was not able to make an exhaustive study of all tasks included in School-Based Assessment at Grade Seven.

\section{Population and Sampling Procedure}

A total of 169 pupils in Form One at three secondary schools in Goromonzi West, Mashonaland East Province participated in this study. Of the total, 77 (45.6\%) were boys and 92 girls (54.4\%). The three secondary schools were selected on the basis of purposive sampling, that is, they were the only ones out of nine schools in Chinamhora, Goromonzi West which had recorded information about their Form One pupils' Grade Seven Mid-Year results on enrolment. In the other six schools, two had administered one-off entrance tests to enroll their pupils into Form One and the remaining four schools had not bothered to record the pupils' Grade Seven results. At such schools, the pupils were only required to bring in their Grade Seven Report Books as evidence that they were in Grade Seven in 2008. To increase power and precision, this study intended to enlist the participation of the whole Form One pupils' population at the three schools. However, many students were dropped from this study due to one or more of the following reasons:

a) Those pupils whose ZIMSEC Grade Seven results were suppressed/not published were left out of the study.

b) The year 2008 was characterized by disruptions to school activities throughout the year hence some primary schools didn’t provide Grade Seven Mid-Year results to their pupils. Such cases were also removed from the study.

c) Some pupils enrolled at the participating schools come from primary schools outside the district and in some instances from outside the province. Due to logistical and economic problems, it wasn't possible to visit these primary schools to get the pupils' ZIMSEC results.

\section{Research Methodology and Data Collection}

This research was carried out using a combination of qualitative and quantitative approaches. The logic is to capitalize on the strengths of the two approaches and compensate for the weaknesses of each approach. According to Punch (1998); Morse, (1991) and Cresswell and Plano Clark (2007), this allows for methodical triangulation where the findings from one type of study can be checked against the findings derived from the other type so as to improve the validity of the results.

Through document analysis, information collected at the three secondary schools included the Form One enrolment figures and the pupils' Grade Seven Mid-Year results. This information was obtained from the pupils' Grade Seven Report Books. Grade Seven ZIMSEC results were obtained from the results lists (Blue Sheets) that are sent to the schools by the Examination Board. Eleven feeder primary schools were visited to obtain this data.

In order to compare the means of the two exam results, T-tests were used. These tests allowed the researchers to detect and find associations between the pupils' performance in the teacher tests and the ZIMSEC tests. The correlations as a linear relationship helped to test for consistency between the Mid-year and ZIMSEC results.

The variables affecting the results were obtained through a questionnaire which had both closed and open-ended items. The data collected from the closed item questions were analysed using the Statistical Packages for Social Scientists (SPSS) Version 16.0. To complement the questionnaires, in-depth interviews using a semi-structured interview guide were carried out with the seven teachers who were teaching the pupils at Grade Seven. These sought to solicit information on the problems the teachers face in the implementation of SBA and whether they had had any formal training in SBA. The data from these interviews and questionnaires were analysed qualitatively by categorizing them into emerging themes for presentation.

\section{Results and Discussion}

A bivariate analysis aimed at establishing the levels of association between the two variables, that is, the Mid-year and the ZIMSEC examination results was carried out. This analysis was used to answer Research Question One which stated that;

> Can School-Based Assessment be used as a reliable instrument of enrolment of students into Form One? 
Table 1. Correlations-Grade Seven ZIMSEC mean grades*Mid- year mean grades

\begin{tabular}{|c|c|c|}
\hline & Aggregate Grade Seven (SBA) & Aggregate Grade Seven (ZIMSEC) \\
\hline Aggregate Grade 7(S.B.A) & 1.000 & $.779^{* *}$ \\
\hline Pearson Correlation & & .000 \\
\hline Sig.(2 tailed) & 132 & 131 \\
\hline $\mathrm{N}$ & & \\
\hline Aggregate & $.779^{* *}$ & 1.000 \\
\hline Seven(ZIMSEC) & .000 & \\
\hline Pedrsonil Correlationil & 131 & 131 \\
\hline Sig.(2 tailed) & & \\
\hline $\mathrm{N}$ & & \\
\hline
\end{tabular}

**Correlation is significant at the 0.001 level (2 tailed).

Table 1 shows a correlation coefficient of 0.779 which indicated that the value was statistically significant. This means that under the Null hypothesis of zero correlation between the two variables, the probability of observing a value of the correlation coefficient as large as 0.779 from the 131 observations was 0.000 . This value was sufficiently small to justify rejecting the Null hypothesis and accepting the alternative hypothesis. This meant that there was a close relationship between the teachers' Grade Seven and the ZIMSEC mean grades.

\subsection{Comparison of the Mid -Year and ZIMSEC Results}

The mean grades obtained by the pupils in the School's Mid-year and the ZIMSEC examinations in each of the subjects (English, Mathematics, Shona and General Paper) were obtained. The results were brought together in order to benchmark the two sets of data. Table 1 below shows how the two compared.

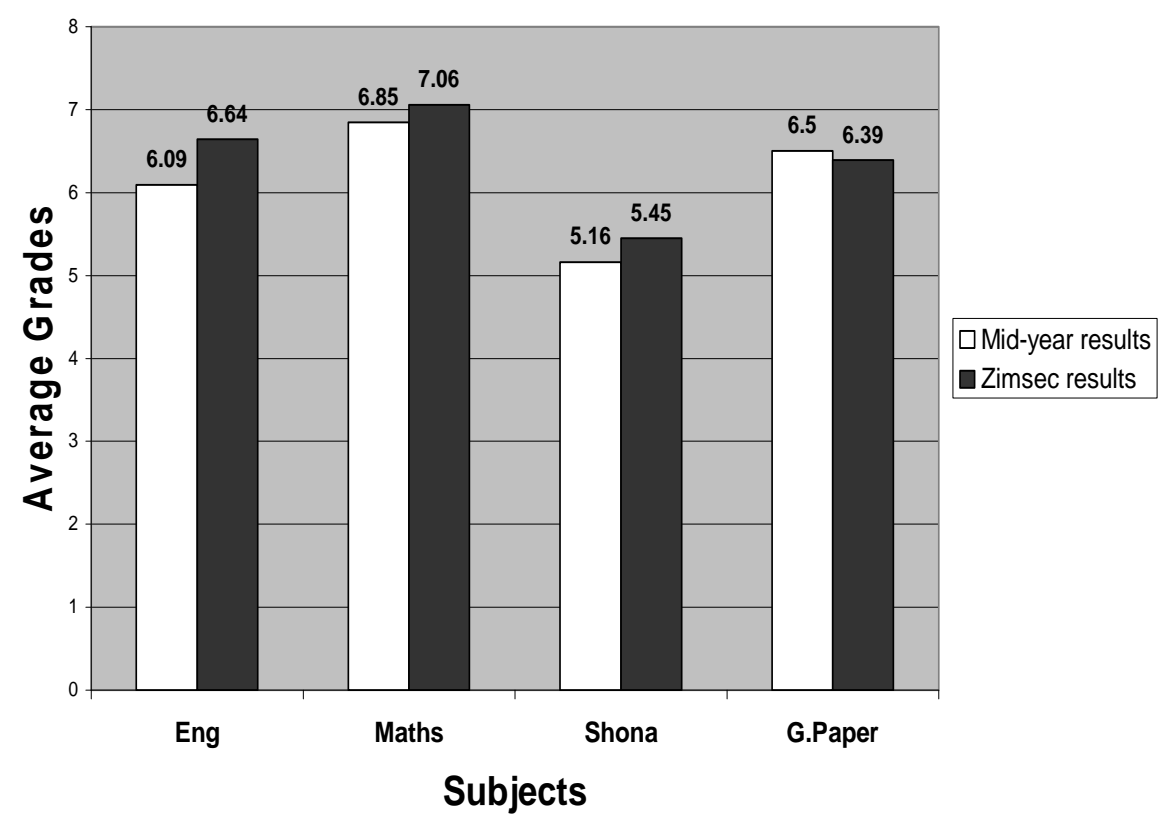

Figure 1. Comparison of mid-year and ZIMSEC results

The information in Figure 1 confirms the results obtained using the Correlations. In the four subjects examined at Grade Seven, the average grades obtained in both the mid- year and ZIMSEC exams in English (6), Shona (5), and General Paper (6) were similar. In Mathematics, the pupils performed slightly better in the Mid-year exams 
(Grade 6, 85) than in the ZIMSEC exams (Grade 7.06). On the other hand, pupils performed better in the midyear examinations in all the other subjects except in General Paper where performance was higher in the ZIMSEC examinations.

These results show that if SBA is given a level playing field, it can be a feasible alternative to the summative (ZIMSEC) exams on recruitment to the next educational level (Dirwai 2004).

\subsection{Preferred Method of Recruitment into Form One}

This part of the analysis answers Research Question (ii) which stated that;

$>$ How do the students view the use of School-Based Assessment results for enrolment into Form One as opposed to the ZIMSEC examination results?

One hundred and twenty-four (124) pupils responded to the question on how they were recruited into Form One. Their responses show that most of them prefer that the ZIMSEC results be used for recruitment into Form One. Sixty pupils (48.4\%) preferred the use of the Grade 7 mid-year tests whilst 64 pupils (51.6\%) wanted the ZIMSEC tests to be used on recruitment into Form One. On the reasons for preferring the use of ZIMSEC tests, some pupils opined that teachers were partial in their assessment of School-Based assignments. For example some respondents supported this assertion by saying that "... even those pupils who were not attending school regularly, managed to pass the mid-year examinations." A female pupil said that she performed badly in the mid-year examinations because the teacher "hated" her whilst another one felt that "... the teachers were biased towards those students whom they liked, that is, there was a lot of favouritism in the SBA results."

These notions support assertions by Kaira, (2005) that continuous assessment results may be consistently higher than those from public examinations and this was attributed to favouritism and teacher biases on gender, socio-economic background or personality.

\subsection{The Level of Training of the Teachers in SBA}

The third research question sought to find out whether the teachers have had any formal training in administering SBA. Views of the seven teachers who were teaching these pupils at Grade Seven were sought in this regard. Although all the teachers were qualified and experienced, none agreed to have had attended any in-service formal training workshop in School based assessment. Those who were examiners with ZIMSEC said that they use some of the knowledge acquired in that exercise to produce test items as well as in their marking. The teachers also point out that it is challenging and tedious to keep pupils' performance records over a long period without the use of computers.

\section{Conclusions and Recommendations}

In the research, it was statistically revealed through the T-tests and correlations that there was some moderate to very strong relationships between the Grade Seven ZIMSEC and Mid-year tests. This means that those pupils who passed teacher tests also passed the ZIMSEC tests. On the strength of this revelation, the teacher tests that were used to enroll pupils into Form One in 2009 were as efficient as the ZIMSEC tests. This allows that School-Based Assessment, when properly applied may be used as a valid instrument of enrollment of pupils into Form One.

Public examinations have been criticised for being too expensive in terms of manpower, time, and financial resources (Mortimore and Mortimore 1984; Mathews, 1985). In order to achieve optimum and efficient use of limited financial resources at the disposal of ZIMSEC, the research recommends that the promotion of pupils into Form One be done using School-Based Assessment results. This will release ZIMSEC from running Grade Seven examinations and channel more resources to the Ordinary and Advanced level examinations.

Findings have shown that Form One pupils at the three schools were in favour of using the ZIMSEC set tests as a method of selection into Form One as opposed to the use of School-Based Assessment tests that were produced by their teachers alleging teacher bias. This was in agreement with the results of researches carried out in Zambia where education stakeholders expressed uneasiness about the use of School-Based Assessment results in the enrollment of Grade eight pupils (Mutanekelwa and Sakala, 2005).

Teachers interviewed in the study lack formal training and skills in assessment. This may affect the production of valid instruments to measure their pupils' performance. This is despite the advice provided by Ogunniyi (1991) and Plake \& Impara (1997) that the successful implementation of continuous assessment hinges upon the quality of the teacher. They point out that findings in many African countries reveal that teachers need adequate knowledge on developing valid and reliable testing instruments, know how to assess non-cognitive aspects of the learning process, how to interpret assessment results as well as the keeping of accurate records. (Kellaghan and 
Greaney, 2004; Kaira, 2005 and Ogunniyi, 1991). To curtail the lack of teacher competence in SBA, there's need to provide continuing professional development to the teachers through pre-service and in-service programmes (Craig and Perraton, 2003and Maramba (2004. Schools should also be equipped with computers for data capture, storage and for mathematical calculations of the learners' performance over the required period. To make this a success, teachers need to be trained in ICT skills for this purpose.

\section{References}

Begum, M. (2008). School Based Assessment.Will it Really Change the Education Scenario in Bangladesh? International Education Studies, 1(2), 45-53. Retrieved from www.ccenet.org/journal/index.php/ies/article/download/885/860

Chetsanga, C. J. (2000). An analysis of the cause and effect of the brain drain in Zimbabwe. Harare: SIRDC. Retrieved from http://www.acpeu.euforic.org/civsoc/by_place/zw.html (June 24, 2011)

Chirume, F., Dirwai, C., \& Masiri, E. (2009). A Rapid Assessment of the 2008 Teaching-Learning and Assessment Processes in Zimbabwe Primary Schools. A Study For Future Educational Interventions. A Research Study. ZIMSEC (funded by UNICEF and SNV) Unpublished. March 2009.

Chisholm, L. (2004). Changing Class. Cape Town: HSRC Press.

Chung, F. (2010). “Chapter Six Education”. In Chimhowu, A.O., Manjengwa, J. and Feresu, S. (2010). Moving Forward in Post-Crisis Zimbabwe, Reducing Poverty and Promoting Sustainable Growth. Harare: IES, 2010. eScholarID:100939

Craig, H., \& Perraton, H. (2003). Open and Distance Education for Continuing Professional Development. In Robinson, B. and Latchem, C. (2003) (eds.). Teacher Education through Open and Distance Learning. New York: Routledge Falmer.

Cresswell, J.W., \& Plano Clark, V.L. (2007). Designing and Conducting Mixed Methods Research. California. Sage Publications.

CSO and UNICEF (2009). Multiple Indicator Monitoring Survey (MIMS). Harare: CSO and UNICEF. surveynetwork.org/surveys/index.php?...SURVEY...2009... - Cached

De Assis, A. B. (2005). Examination malpractices in General education in Mozambique. Paper presented at the $3^{\text {rd }}$ Sub-regional Conference on Assessment. Mangochi: Malawi National Examinations Board.

Dirwai, C. (2004). Role of the teacher in School/Site Based Assessment in Zimbabwe. Paper presented at the $2^{\text {nd }}$ Sub-regional Conference on Assessment. Victoria Falls: Zimbabwe Schools Examinations Council.

Kaira, L. (2005). Role of Assessment in the Promotion of the Learning Process. Paper presented at the $3^{\text {rd }}$ Sub-regional Conference on Assessment. Mangochi: Malawi National Examinations Board.

Kellaghan, T., \& Greaney, V. (2004). Assessing Student Learning in Africa. Washington D.C.; World Bank.

Maramba, J.C. (2004). School-Based Assessment: A Theoretical Perspective. Paper presented at the $2^{\text {nd }}$ Sub-regional Conference on Assessment. Victoria Falls: Zimbabwe Schools Examinations Council.

Maravanyika, O.E. (2004). Ethno-based learning and Culture in a Multi- ethnic and Multi-cultural Environment. Paper presented at the $2^{\text {nd }}$ Sub-regional Conference on Assessment. Victoria Falls: Zimbabwe Schools Examinations Council.

Masole, T.M. (2004). Quality Assurance and Control of School-Based Assessment for Agriculture in Junior Secondary School. Paper presented at the $2^{\text {nd }}$ Sub-regional Conference on Assessment. Victoria Falls: Zimbabwe Schools Examinations Council.

Mathews, J.C. (1985). Examinations. London: George Allen and Unwin.

Monageng, E.L., \& Pillay, S.S. (2005). Challenges in the Quality Assurance of Continuous Assessment within the South African Education System. Paper presented at the $3^{\text {rd }}$ Sub-regional Conference on Assessment. Mangochi: Malawi National Examinations Board.

Morse, J.M. (1991). Approaches to qualitative-quantitative methodological triangulation. Nursing Research, 40, 120-123.

Mortimore, J., \& Mortimore, P. (1984). Secondary School Examinations. London: Institute of Education. University of London. 
Mtetwa, D.K., Makamure, R., Kwari, R., \& Chipangura, A. (2003). Science Education In-Service Teacher Training (SEITT) and Better Schools Programme Zimbabwe (BSPZ) Resource Teachers' modes of facilitating In-Service Activity. Zimbabwe Journal of Educational Research. 15(2), 75-83.

Mutanekelwa, N.N., \& Sakala, C.T. (2005). Promoting Learning Through Assessment: The Zambian Experience. Paper presented at the $3^{\text {rd }}$ Sub-regional Conference on Assessment. Mangochi: Malawi National Examinations Board.

Ndabi, D.M. (2004). Quality Assurance and Control of School-Based Assessment in Tanzania Secondary Schools. Paper presented at the $2^{\text {nd }}$ Sub-regional Conference on Assessment. Victoria Falls: Zimbabwe Schools Examinations Council.

Nitko, A.J. (2004). Educational Assessment of Students. New Jersey: Pearson Education.

Ogunniyi, M.B. (1991). Educational Measurement and Evaluation. Nigeria: Longman.

Plake, B.S., \& Impara, J.C. (1997). Teacher Assessment Literacy: What do teachers know about assessment? In Phye, G.D. (ed.) Handbook of Classroom Assessment, Learning, Achievement and Adjustment. San Diego: Academic Press.

Punch, K.F. (1998). Introduction to Social Research: Quantitative and Qualitative Approaches. London: Sage

Rubadiri, D. (2005). Keynote Address. $3^{\text {rd }}$ Sub-regional Conference on Assessment. Mangochi: Malawi National Examinations Board.

Shizha, E., \& Kariwo, M. T. (2011). Education and Development in Zimbabwe. A social, political and economic analysis. www.amazon.com > ... > Education \& Reference > Education - Cached.

Sommerset, A., (1987). Examination Reform in Kenya. Washington D. C.: World Bank.

Tirivarombo, S. (2004). Ethno-based Technologies and Traditional Lifestyles in Education. Paper presented at the $2^{\text {nd }}$ Sub-regional Conference on Assessment. Victoria Falls: Zimbabwe Schools Examinations Council.

Zvobgo, R. J. (1997). The State, Ideology and Education. Gweru: Mambo Press.

\section{Web References}

http://curriculum.wcape.school.za/resourcefiles 